\title{
HACIA UN MODELO SEMIÓTICO PARA LA TEORÍA DEL CUENTO
}

\section{Lauro Zavala}

\author{
UAM Xochimilco, México
}

\section{INTRODUCCIÓN: DE LA TEORÍA A LA META-TEORÍA}

Durante los últimos años se ha intensificado en varias lenguas el interés por la reflexión sistemática acerca del cuento literario. Se han publicado varias compilaciones especializadas, orientadas a estudiar aspectos específicos del género (May, 1994; Fröhlicher-Güntert, 1995; Engel, 1995), a reunir definiciones de carácter general de (De Vallejo, 1989; Lohafer-Clarey, 1989; Pacheco-Barrera Linares, 1993) o a sistematizar las poéticas de los cuentistas, a partir de su experiencia de escritura (Current-García-Patrick, 1974; Charters, 1995; Zavala, 1993, 1994, 1996).

Sin embargo, aún es necesario contar con un modelo lo suficientemente flexible para incorporar la diversidad de elementos constitutivos y las múltiples estrategias de construcción de un objeto tan ubicuo como el cuento. En particular, es posible pensar en la existencia de un 
meta-modelo que permita incorporar en su interior las explicaciones propiamente teóricas y las construcciones poéticas de carácter heurístico que producen los autores durante el proceso de la escritura.

\section{UN GÉNERO DE ESCRITURA Y TRES ESTRATEGIAS DE LECTURA}

En este trabajo presento un modelo ternario para el estudio de las teorías del cuento, derivado del modelo semiótico de Peirce. A partir de la distinción semiótica entre estrategias deductivas, inductivas y abductivas de argumentación, es posible reconocer la existencia de tres estrategias para la definición de un cuento. Estas estrategias pueden ser llamadas, respectivamente, normativa, casuística e inferencial.

Este modelo ternario tiene una naturaleza pragmática, y se deriva de una reflexión sobre los procesos de lectura y escritura que los lectores y autores ponen en práctica durante la interpretación de textos concretos. Como se verá más adelante, estos procesos están muy ligados al acto nominativo, que a su vez tiene consecuencias lógicas por el solo acto de llamar a algo un «cuento».

Las características generales de cada una de estrategias (normativa, casuística e inferencial) en la lectura y escritura de un cuento son las siguientes:

a) Estrategia normativa. Desde esta perspectiva, un texto puede ser reconocido como un cuento literario a partir de un sistema deductivo (por medio de abducciones hipercodificadas), es decir, a partir de una o varias definiciones canónicas, establecidas como parte de un sistema de representación del corpus genérico. Un cuento es lo que dictan la definiciones.

b) Estrategia casuística. Desde esta perspectiva, un texto puede ser interpretado como un cuento literario a partir de un sistema inductivo (por medio de abducciones hipocodificadas), es decir, a partir de una o varias lecturas que ponen en juego estrategias de comprensión derivadas del horizonte de expectativas del lector (o de la comunidad interpretativa a la que pertenece). Un cuento es lo que los lectores interpretan como tal. 
c) Estrategia conjetural. Desde esta perspectiva, un texto puede ser construido como un cuento literario a partir de un sistema de abducciones propiamente dichas (de naturaleza creativa), es decir, a partir de la formulación de inferencias derivadas del reconocimiento de improntas, síntomas e indicios de lo que puede ser considerado como un cuento. Un cuento es todo aquello que llamamos «cuento».

Esta última estrategia permite reconocer todas las formas posibles que puede adoptar el género, ya que incorpora los elementos propios de las otras estrategias (la normatividad genérica y la experiencia particular de cada lectura), asimilando además las formas experimentales de la escritura literaria. Este es el modelo que permite releer irónicamente la tradición y reescribirla en formas inéditas. Este es el modelo que está más próximo a la experiencia misma de la escritura literaria, y de la escritura crítica acerca de los cuentos.

Se trata de una estrategia que permite negociar elementos pertenecientes al horizonte de la experiencia y al horizonte de las expectativas, al universo del lector individual y al de las comunidades interpretativas, y en la que el lector, a partir de su experiencia personal (secundariedad), utiliza su familiaridad con la norma (terceriedad) y genera un texto nuevo (primariedad).

\section{LA LECTURA COMO ABDUCCIÓN: DE LA NOMINACIÓN A LA GENERACIÓN TEXTUAL}

En el caso de lo que llamamos «cuento», entonces, las formas en las que un texto es reconocido, interpretado o construido como cuento literario pueden ser puestas en práctica al leer un texto breve cualquiera. En cada caso (reconocimiento, interpretación o construcción) las características que distinguen un cuento de otra clase de texto escrito atraviesan por procesos y criterios de validación distintos entre sí, dependiendo de que partan, respectivamente, de una regla (deductivamente), de un caso (inductivamente) o de un resultado (abductivamente).

Las características textuales que pueden ser reconocidas, interpretadas o construidas a partir de la adopción de cada una de estas res- 
pectivas estrategias pueden ser de naturaleza formal (como la extensión del texto), de naturaleza estructural (como las funciones del título, del inicio y del final del texto) y de naturaleza propiamente narrativa (como el perfil de los personajes, la construcción de la instancia narrativa, el empleo de convenciones genéricas y el tratamiento del tiempo y el espacio dentro del texto). Cada uno de estos elementos es reconocido, interpretado o construido de manera diferente desde cada una de las perspectivas señaladas (normativa, casuîstica o inferencial).

La estrategia normativa presupone que cualquier texto que cumple ciertas condiciones formales, estructurales y narrativas, por definición es un cuento. Desde esta perspectiva, la brevedad misma del texto responde a parámetros específicos, que varían según la preceptiva adoptada. Sin embargo, cada una de estas preceptivas ha surgido a partir de observaciones casuísticas, es decir, cada una de ellas se ha establecido a partir de la existencia de una tradición (de textos publicados) dentro de la cual se ha decidido llamar «cuento» a aquello que tiene una determinada extensión. Y este acto nominativo, a su vez, ha surgido a partir de la necesidad de distinguir textos con características distintas del cuento de tradición oral, de la poesía y de la novela, que son los géneros próximos ante los cuales resulta necesario establecer diferencias específicas. En otras palabras, el proceso que ha llevado a la creación de normas genéricas ha tenido su origen en condiciones contingentes, precisamente a partir de una lógica casuística.

A su vez, la adopción de estrategias casuísticas se ha apoyado, en un principio, en una lógica inferencial, la cual es necesaria precisamente durante el acto de creación (literaria o crítica) y en el proceso de evolución de las formas narrativas y de las formas de lectura de textos concretos en condiciones históricas particulares.

Así, una vez creada una norma conceptual a partir de una tradición textual, la estrategia de reconocimiento normativo se pone en juego frente a cualquier nuevo texto. Pero la naturaleza necesariamente impredecible de la creación textual y la naturaleza conjetural de toda lectura crítica determinan que sea posible reestructurar de manera periódica por lo menos algunos elementos del sistema normativo, en función de textos e interpretaciones que no se apeguen a las reglas existentes en un momento particular, y que, sin embargo, tampoco puedan ser adscritos como pertenecientes a otros géneros discursivos. 
En este contexto, en términos generales, un cuento clásico podría estar definido en el rango que va de las 2.000 a las 10.000 palabras, lo cual significa, aproximandamente, entre 10 y 50 páginas impresas. Sin embargo, existen lectores, editores y críticos para los cuales es posible llamar «cuento» a textos narrativos que tengan una extensión menor (o, incluso, mayor) a este rango. Es así como se han creado categorías como cuento «corto» (1.000-2.000 palabras), «muy corto» (200-1.000 palabras) y ultracorto (1-200 palabras).

\section{UN MODELO TERNARIO Y LA RETÓRICA DE LA LECTURA}

El empleo de una u otra estrategia para la definición de un texto como cuento está organizado, lógicamente, como se muestra a continuación:

a) Estrategia normativa (nomotética): una regla y un caso para un resultado.

Regla: Los textos con estas características son cuentos.

Caso: Este texto tiene estas características.

Resultado: Este texto es un cuento.

b) Estrategia casuística (historiográfica): repetir experiencias (casos) para observar resultados y probar (o disprobar) una regla.

Caso: Este texto tiene estas características.

Resultado: Este texto es un cuento.

Regla: Los textos con estas características son cuentos.

c) Estrategia conjetural (abductiva): a partir de evidencias (resultados) ensayar diversas hipótesis (reglas) que permitan reconstruir el objeto (resolver el caso).

Resultado: Este texto es un cuento.

Regla: Los textos con estas características son cuentos.

Caso: Este texto tiene estas características. 
Precisamente en la abducción, la decisión de considerar que un texto particular es un cuento implica una decisión a la vez generativa y nominativa, ya que el acto de llamar «cuento» a un texto determinado presupone la construcción (o la adopción) de una regla, que puede ser generada por el acto mismo de llamar a un texto específico «cuento» y no otra cosa. Así, por ejemplo, un editor en la contraportada de un libro, un lector durante el acto de comentar lo que está leyendo o un escritor durante el proceso de creación pueden llamar «cuento» a un texto que otro editor, lector o escritor podrían llamar, respectivamente, «diálogo dramático», «relato» o «poema en prosa».

Aquí podría señalarse que el acto nominativo es un acto de secundariedad en la medida en que constituye un resultado, es decir, constituye una experiencia concreta. Y en esa medida puede ser considerado como un indicio (de la existencia de un cuento), precisamente porque el efecto precede a la causa en una relación de contigüidad posible.

Además, podría añadirse que todo acto nominativo, desde una perspectiva abductiva, presupone un acto generativo, en la medida en que es posible llamar a un texto «cuento» sólo si tiene determinadas características. La generación de reglas propias para cada caso nominativo convierte al acto de llamar a un texto «cuento» y no otra cosa, un acto de terceriedad condicionada por un caso particular.

La abducción conjetural, como ha sido señalado por numerosos autores, se construye al producir una interpretación que reconoce la existencia de una serie de elementos de la realidad a los que podemos considerar como improntas, es decir, como elementos sinecdóquicos que pueden ser reconstruidos bajo una denominación particular a partir de inferencias igualmente fragmentarias.

\section{LA ABDUCCIÓN NOMINATIVA COMO UN ACTO PERFORMATIVO}

Veamos un ejemplo concreto de abducción nominativa. Si encuentro un texto de una sola palabra, que forma parte de «un libro de cuentos», con un título propio y al final de una serie de cuentos, puedo inferir como síntoma, es decir, como reconocimien- 
to de una contigüidad necesaria entre efecto y causa, que existe una instancia editorial (el autor del libro, al incluir este texto en la colección) que ha decidido incluir este texto bajo el nombre común de «cuentos».

Por otra parte, también puedo reconocer algunas improntas acerca de la existencia de un cuento (como inferencias sinecdóquicas a partir de otros indicios). La primera de estas improntas es el hecho de que el texto forma parte de un libro cuyo título es Infundios ejemplares. Ello indica que en el libro hay diversos infundios, es decir, ficciones (o cuentos). Pero también anuncia el proyecto estructural de la ordenación de los textos, pues éstos se presentan en un orden que va del que tiene mayor extensión (dos páginas) al de menor extensión (una palabra), como si se tratara de un embudo textual. El libro, entonces, no sólo contiene infundios sino que tiene una estructura infundibuliforme (del más extenso al más corto).

El texto en cuestión tiene como título «Dios», y contiene una sola palabra: precisamente la misma del título. Una lectura deductiva, canónica, del texto en cuestión, podría hacer pensar que no se trata de un cuento, puesto que no hay una narración evidente, no hay una construcción explícita de personajes, no rebasa la extensión mínima de dos mil palabras, y no hay un tratamiento genérico de las convenciones narrativas que permitan reconocer la naturaleza de este texto. Desde esta perspectiva lógica, este texto no es un cuento.

Una lectura inductiva llevaría a pensar que la naturaleza del texto depende de la consideración o la exclusión de los otros elementos contextuales que rodean al texto, pues la consideración de algunos de ellos podría llevar a incorporar una serie de elementos implícitos que sólo un lector interesado en tomarlos en cuenta en su lectura genérica los habrá de incorporar para emitir un juicio de carácter genológico, es decir, para determinar si se trata de un cuento o no.

Una lectura abductiva podría partir de la interpretación de que el texto más breve puede ser el más extenso, precisamente porque, como en la radio, deja al lector la posibilidad de recrear, a partir de un solo término, y por la propia naturaleza semántica de éste, diversos universos textuales. Por último, y como se señala en la contraportada del mismo libro, con este texto se llega al «mayor infundio teológico». 


\section{LEER Y ESCRIBIR NO EQUIVALEN A TEORIZAR Y ANALIZAR}

La frecuencia con la que desde el sentido común se confunden las tres estrategias de sentido que aquí han sido señaladas tiene gran importancia en la filosofía de las ciencias sociales y en la teoría y el análisis literario. En ambos casos, distinguir entre la estrategia abductiva y la deductiva permite distinguir entre tener la experiencia y entender esta experiencia, es decir, entre escribir un cuento y reconocer los elementos que distinguen un cuento de otro o un cuento de otra clase de textos. Una consecuencia de no establecer claramente esta distinción consiste en presuponer que quien escribe un cuento entiende la experiencia de escribir o reconoce las características de un cuento mejor que quien no escribe cuentos.

Sin embargo, no es necesario ser cuentista para entender lo que es un cuento. Creer lo contrario es adoptar una tesis solipsista, en la que se confunde una causa necesaria (escribir un cuento) con unos efectos posibles (la interpretación del proceso y la interpretación del producto). En este contexto es frecuente confundir el origen de las huellas, los síntomas y los indicios (como elementos sinecdóquicos de lo que llamamos «cuento») con las relaciones de causalidad posible y necesaria entre efecto y causa, es decir, con el análisis de un cuento y con la teoría del cuento en general.

En otras palabras, la distinción que aquí proponemos entre las estrategias deductiva, inductiva y abductiva para la teoría del cuento es similar a la distinción mucho más general que existe entre teoría, análisis y creación literaria. La teoría propiamente dicha (que aquí tendríamos que llamar «metateoría») es deductiva; el análisis sistemático sigue una lógica inductiva, y la lectura y la escritura son actividades necesariamente abductivas.

A partir de esta distinción podemos distinguir entre la adopción de modelos y definiciones genológicas pertenecientes a la formulación teórica propiamente dicha (como actividad de naturaleza deductiva, a partir de reglas aplicables a todos los casos); el reconocimiento de elementos específicos en textos concretos, propio del análisis (como actividad de naturaleza inductiva y experimental, a partir del examen de elementos particulares en textos concretos), y la proyección probabilística de relaciones de causalidad posible entre texto e intención, propios de la creación literaria (como actividad de naturaleza asintótica y aproximativa, es decir, abductiva). 
La lectura cuidadosa de las poéticas escritas por los cuentistas lleva a la conclusión de que los autores de cuentos suelen escribir textos de una gran calidad literaria cuando escriben acerca de su experiencia de escritura. Pero la lectura de estos textos, en los que cada escritor escribe acerca de su experiencia de escritura, no necesariamente contribuye al análisis o la teorización de lo que llamamos «cuento», pues la producción de análisis y de teorías depende de la interpretación de elementos particulares o del reconocimiento de elementos generales, respectivamente, y estas actividades no están garantizadas por la escritura misma. Escribir no es lo mismo que leer, ni tampoco es lo mismo que escribir acerca de la experiencia de escribir. Un plano de la experiencia no garantiza familiaridad con otro plano radicalmente distinto.

\section{CONCLUSIÓN: UN TEXTO ES LEÍDO SEGÚN EL CRISTAL SEMIÓTICO CON QUE SE MIRA}

Una consecuencia de la adopción del modelo semiótico consiste en la posibilidad de reconocer de manera persuasiva la naturaleza literaria de textos narrativos breves que canónicamente no han sido considerados como cuentos, como es el caso de los hipertextos, los etnocuentos, las crónicas de viaje, los cuentos ultracortos y algunas formas de escritura paródica, híbrida y metaficcional.

Cada una de estas estrategias para el estudio, la lectura o la escritura de un cuento puede ser utilizada de manera similar para el estudio, la lectura o la escritura de cualquier texto cultural, ya sea escrito o de otra naturaleza. De esta manera, es posible pensar en la creación de modelos semióticos para el estudio de las diversas lecturas posibles de textos de naturaleza sartorial, proxémica, cinematográfica, musical, arquitectónica o cualquier otra.

Los límites de la interpretación, sin embargo, están determinados por la imaginación de los lectores.

\section{Referencias bibliográficas}

Charters, ANn (ed.) (1995). The Story and Its Writer. Boston: Bedford Books of St. Martin's Press. 
Current-García, Eugene Walton S. Patrick (eds.) (1974). What Is the Short Story? Glenview, Scott: Foresman and Co.

ECO, UMBERTO (1992). «Cuernos, cascos, zapatos: tres tipos de abducción». En Los límites de la interpretación, 254-282. México: Lumen.

ENGEL, VINCENT (ed.) (1995). Le genre de la nouvelle dans le monde francophone au tournant du XXIe siècle. Québec: L'instant même.

FröliCher, PETER-GeORGES GÜNTERT (comps). (1995). Teoría e interpretación del cuento. Berna, Lang: Perspectivas Hispánicas.

Golwarz, SERgio (1967). Infundios ejemplares. México: FCE.

Lohafer, Susan Jo Ellyn Clarey (eds.) (1989). Short Story Theory at a Crossroads. Baton Rouge and London: Louisiana State University Press.

May, Charles E. (ed.) (1994). The New Short Story Theories. Athens: Ohio University Press.

Pacheco, Carlos-Luis Barrera Linares (comps.) (1993). Del cuento y sus alrededores. Caracas: Monte Ávila Editores Latinoamericana.

PAVÓN, Alfredo (comp.) (1986). El cuento está en no creérselo. Tuxtla Gutiérrez: Universidad Autónoma de Chiapas.

- (comp.) (1987). Teoría y práctica del cuento. Encuentro Internacional 1987. Morelia: Instituto Michoacano de Cultura.

Peirce, Charles Sanders (1955). «Abduction and induction». En Philosophical Writings of Peirce, J. Buchler (ed.), 150-156. New York: Dover.

Vallejo, Catharina V. DE (comp.) (1989). Teoría cuentística del siglo XX. (Aproximaciones hispánicas). Miami: Ediciones Universal.

ZavalA, LAURo (comp.) (1993). Teorías del cuento I: Teorías de los cuentistas. México: UNAM, ${ }^{2} 1995$.

- (comp.) (1995). Teorías del cuento II: La escritura del cuento. México: UNAM, ${ }^{2} 1996$.

- (comp.) (1996). Teorías del cuento III: Poéticas de la brevedad. México: UNAM.

- (1996). «El cuento ultracorto: hacia un nuevo canon literario». En $E l$ cuento mexicano. Homenaje a Luis Leal, S. Poot Herrera (ed.), 165181. México: UNAM. 